\title{
Spine stereotactic radiosurgery for metastatic sarcoma: patterns of failure and radiation treatment volume considerations
}

\author{
Andrew J. Bishop, MD, ${ }^{1}$ Randa Tao, MD, ${ }^{1}$ B. Ashleigh Guadagnolo, MD, MPH, ${ }^{1}$ \\ Pamela K. Allen, PhD, ${ }^{1}$ Neal C. Rebueno, CMD, ${ }^{2}$ Xin A. Wang, PhD, ${ }^{3}$ Behrang Amini, MD, PhD, ${ }^{4}$ \\ Claudio E. Tatsui, MD, ${ }^{5}$ Laurence D. Rhines, MD, ${ }^{5}$ Jing Li, MD, PhD, ${ }^{1}$ Eric L. Chang, MD, ${ }^{6}$ \\ Paul D. Brown, MD, ${ }^{1}$ and Amol J. Ghia, MD ${ }^{1}$
}

\begin{abstract}
Departments of ${ }^{1}$ Radiation Oncology, ${ }^{2}$ Radiation Dosimetry, ${ }^{3}$ Radiation Physics, ${ }^{4}$ Diagnostic Radiology, and ${ }^{5}$ Neurosurgery, The University of Texas MD Anderson Cancer Center, Houston, Texas; and ${ }^{6}$ Department of Radiation Oncology, USC Norris Cancer Hospital, Keck School of Medicine of USC, Los Angeles, California
\end{abstract}

OBJECTIVE Given the relatively lower radiosensitivity of sarcomas and the locally infiltrative patterns of spread, the authors sought to investigate spine stereotactic radiosurgery (SSRS) outcomes for metastatic sarcomas and to analyze patterns of failure.

METHODS The records of 48 patients with 66 sarcoma spinal metastases consecutively treated with SSRS between 2002 and 2013 were reviewed. The Kaplan-Meier method was used to estimate rates of overall survival (OS) and local control (LC). Local recurrences were categorized as occurring infield (within the 95\% isodose line [IDL]), marginally (between the $20 \%$ and $95 \%$ IDLs), or out of field.

RESULTS Median follow-up time was 19 months (range 1-121 months), and median age was 53 years (range 17-85 years). The most commonly treated histology was leiomyosarcoma (42\%). Approximately two-thirds of the patients were treated with definitive SSRS (44 [67\%]) versus postoperatively (22 [33\%]). The actuarial 1-year OS and LC rates were $67 \%$ and $81 \%$, respectively. Eighteen patients had a local relapse, which was more significantly associated with postoperative SSRS $(p=0.04)$. On multivariate modeling, receipt of postoperative SSRS neared significance for poorer LC $(p=0.06$, subhazard ratio [SHR] 2.33), while only 2 covariates emerged as significantly correlated with LC: 1) biological equivalent dose (BED) > 48 Gy (vs BED $\leq 48$ Gy, $p=0.006$, SHR 0.21) and 2) single vertebral body involvement (vs multiple bodies, $p=0.03$, SHR 0.27). Of the 18 local recurrences, $14(78 \%)$ occurred at the margin, and while the majority of these cases relapsed within the epidural space, 4 relapsed within the paraspinal soft tissue. In addition, 1 relapse occurred out of field. Finally, the most common acute toxicity was fatigue ( 15 cases), with few late toxicities (4 insufficiency fractures, 3 neuropathies).

CONCLUSIONS For metastatic sarcomas, SSRS provides durable tumor control with minimal toxicity. High-dose single-fraction regimens offer optimal LC, and given the infiltrative nature of sarcomas, when paraspinal soft tissues are involved, larger treatment volumes may be warranted.

https://thejns.org/doi/abs/10.3171/2017.1.SPINE161045

KEY WORDS spine metastasis; sarcoma; stereotactic body radiation therapy; spine stereotactic radiosurgery; SSRS; oncology 
$\mathrm{S}$ ARCOMAS have a high propensity for distant metastasis. Approximately $30 \%$ of patients presenting with localized sarcomas will eventually develop distant disease, and about $10 \%$ of patients have metastases at the time of presentation., ${ }^{7,30}$ The most common site for metastasis is the lung parenchyma, with spinal disease developing in a smaller proportion of patients. However, sarcoma spinal metastases represent a dominant source of morbidity and negatively impact quality of life as a result of cancer-related, neuropathic, or mechanical pain; pathological fracture; and spinal cord compression. ${ }^{8}$ Therefore, aggressive local therapy with either radiation therapy (RT) or surgical intervention is often needed to control symptoms, preserve function, and enhance local tumor control.

Spine stereotactic radiosurgery (SSRS) has become a widely adopted conformal method of delivering high, ablative doses of RT for metastatic spinal disease. Among all cancer types, SSRS offers a favorable risk-benefit profile while providing 1-year local control (LC) rates generally above $85 \% .{ }^{1,3,5,13,14,23,25,29}$ However, there are limited data on the efficacy of SSRS for the treatment of metastatic sarcoma. Among the few published reports are inconsistent tumor control rates ranging between $51 \%$ and $88 \%$ at 1 year. ${ }^{6,10,18,19}$ Notably, the lower tumor control rates in this range are not dissimilar to the rates expected from conventional fractionation. ${ }^{2,10,14,16,22}$ Therefore, if these outcomes truly reflect the course of sarcoma spinal metastases following SSRS, why is tumor control poorer for this histological entity?

Perhaps the explanation is related to the biology of sarcomas, or perhaps it is related to treatment delivery. There is an interesting philosophical and arguably incongruent difference in the therapeutic approach between highly conformal SSRS and the wide-margin, large-volume conventional fractions used for primary sarcomas. ${ }^{9,15,27}$ Given the propensity of primary sarcomas to recur in the soft tissue when inadequate radiation field margins are used, it may be necessary to modify SSRS treatment fields for this histology in the metastatic setting. To better understand the efficacy of SSRS for metastatic sarcomas, we reviewed our experience to investigate tumor control outcomes and better characterize patterns of failure to aid in strategies for improved LC.

\section{Methods \\ Patients}

We identified 48 consecutive patients with 66 sarcoma spinal metastases treated with SSRS at the University of Texas MD Anderson Cancer Center during the period between 2002 and 2013. Thirty-five of the lesions (53\%) had been treated in 3 institutional Phase I/II trials evaluating single- and multifraction SSRS for spinal metastases. ${ }^{5,11,12}$ After obtaining approval from the institutional review board, we extracted patient, tumor, and outcome characteristics from the medical records for the entire group.

\section{Treatment}

All patients were treated using CT-guided intensitymodulated SSRS using the CT-on-rails EXaCT targeting system or Trilogy treatment delivery system with on-board cone-beam CT (Varian Medical Systems), as previously described. ${ }^{4,21}$ After patients were immobilized in an Elekta BodyFix stereotactic body frame (Elekta) and aligned using a CT-on-rails (GE Healthcare) or cone-beam CT, treatments were delivered typically using a 9-field stepand-shoot intensity-modulated radiation treatment plan. Each procedure was monitored by the treating radiation oncologist and a dedicated radiation physicist to verify target positioning and quality assurance.

Metastatic spinal tumors were treated with various doses and fractionations. Given that the first institutional protocols established safety and efficacy, the regimens investigated were more conservative. However, more contemporary patients were treated with standardized regimens based on tumor radiosensitivity and previous RT. Contouring of the gross tumor volume (GTV) and clinical target volume (CTV) was consistent with recent consensus guidelines for SSRS (not specific to histology). ${ }^{9}$ The GTV was defined as visible tumor on an MR image fused with the planning CT scan, and the CTV, which contains the GTV, was defined as at-risk contiguous bone marrow or soft-tissue margin in cases with paraspinal extension of disease. The planning treatment volume (PTV) was defined with no margin to the CTV. The dose was commonly normalized between the $80 \%$ and $90 \%$ isodose line, ${ }^{21}$ so that the prescription line enclosed the PTV, except near the spinal cord as necessary. Postoperative SSRS target delineation began with fusion of the preoperative MR image to the planning CT scan. The GTV was defined as any residual disease and/or the postoperative bed. The CTV was defined as the GTV with contiguous bone marrow space and any additional postoperative bed at risk for harboring microscopic disease. Additional radiation details and outcomes of postoperative SSRS were recently published by Tao and colleagues. ${ }^{26}$ To account for the various fractionation schemes, a biological equivalent dose (BED) was calculated for the prescription based on the $\alpha / \beta$ value of $10 \mathrm{~Gy}$ for tumor effect.

\section{Follow-Up and Relapses}

The median follow-up for the entire cohort was 19 months (range 1-121 months) and for all living patients 31 months (range 10-121 months). Acute (defined as less than 3 months) and long-term toxicities were prospectively recorded for patients treated on protocol (53\%); otherwise, toxicities were retrospectively graded using the Common Terminology Criteria for Adverse Events (CTCAE) version 4.03 .

Patients were seen every 3 months for physical examination and MRI of the spine to assess for radiological tumor recurrence. Local recurrences were defined as radiological evidence of progression as identified by the reading radiologist. After confirmation by the radiation oncologist, local recurrences were subclassified based on anatomical location of the tumor recurrence (epidural space vs paraspinal) and its proximity to isodose lines. Infield relapses were defined as being entirely encompassed within the 95\% isodose line, whereas marginal relapses occurred partially or fully in the penumbra commonly between the $20 \%$ and $95 \%$ prescription isodose lines. 
TABLE 1. Patient and disease characteristics

\begin{tabular}{|c|c|c|c|c|}
\hline \multirow[b]{2}{*}{ Variable } & \multicolumn{3}{|c|}{ №. $(\%)$} & \multirow{2}{*}{$\begin{array}{c}\mathrm{p} \\
\text { value }\end{array}$} \\
\hline & All Tumors & Recurrence & No Recurrence & \\
\hline No. & 66 & 18 & 48 & \\
\hline \multicolumn{5}{|l|}{$\begin{array}{l}\text { Time from CA Dx to } \\
\text { spine met in mos }\end{array}$} \\
\hline Median & 36 & 26 & 42 & 0.78 \\
\hline Range & $0-264$ & $0-101$ & $0-264$ & \\
\hline \multicolumn{5}{|l|}{$\begin{array}{l}\text { Age at time of } \\
\text { SSRS in yrs }\end{array}$} \\
\hline Median & 53 & 51 & 56 & 0.78 \\
\hline Range & $17-85$ & $17-79$ & $17-85$ & \\
\hline \multicolumn{5}{|l|}{ Sex } \\
\hline Male & $31(47)$ & $8(26)$ & $23(74)$ & 1.0 \\
\hline Female & $35(53)$ & $10(28)$ & $25(71)$ & \\
\hline \multicolumn{5}{|l|}{ Tumor type } \\
\hline Leiomyosarcoma & $28(42)$ & $9(32)$ & $19(68)$ & NA \\
\hline Epithelioid & $9(14)$ & $1(11)$ & $8(89)$ & \\
\hline MFH/UPS & $8(12)$ & $1(12)$ & $7(88)$ & \\
\hline $\begin{array}{l}\text { Chondrosar- } \\
\text { coma }\end{array}$ & $6(9)$ & $3(50)$ & $3(50)$ & \\
\hline $\begin{array}{l}\text { Solitary fibrous } \\
\text { tumor }\end{array}$ & $5(8)$ & $0(0)$ & $5(100)$ & \\
\hline $\begin{array}{l}\text { Myxoid liposar- } \\
\text { coma }\end{array}$ & $5(8)$ & $1(20)$ & $4(80)$ & \\
\hline Osteosarcoma & $3(4)$ & $1(33)$ & $2(67)$ & \\
\hline $\begin{array}{l}\text { Dediff liposar- } \\
\text { coma }\end{array}$ & $1(2)$ & $0(0)$ & $1(100)$ & \\
\hline Ewing's & $1(2)$ & $1(100)$ & $0(0)$ & \\
\hline \multicolumn{5}{|l|}{$\begin{array}{l}\text { Spine section af- } \\
\text { fected }\end{array}$} \\
\hline Cervical & $10(15)$ & $3(30)$ & $7(70)$ & 0.79 \\
\hline Thoracic & $40(61)$ & $10(25)$ & $30(75)$ & \\
\hline Lumbosacral & $16(24)$ & $5(31)$ & $11(69)$ & \\
\hline \multicolumn{5}{|l|}{$\begin{array}{l}\text { Bilsky grade at time } \\
\text { of SSRS }\end{array}$} \\
\hline 0 & 23 & 4 & 19 & 0.67 \\
\hline $1 a$ & 19 & 6 & 13 & \\
\hline $1 b$ & 15 & 6 & 9 & \\
\hline 1c & 4 & 1 & 3 & \\
\hline 2 & 4 & 1 & 3 & \\
\hline 3 & 1 & 0 & 1 & \\
\hline \multicolumn{5}{|l|}{ Previous RT } \\
\hline Yes & $11(17)$ & $2(18)$ & $9(82)$ & 0.71 \\
\hline No & $55(83)$ & $16(29)$ & $39(71)$ & \\
\hline \multicolumn{5}{|l|}{$\begin{array}{l}\text { Vertebral body } \\
\text { count }\end{array}$} \\
\hline Single & $48(73)$ & $10(21)$ & $38(79)$ & 0.07 \\
\hline Multiple & $18(27)$ & $8(44)$ & $10(56)$ & \\
\hline \multicolumn{5}{|l|}{ Treatment type } \\
\hline Definitive & $44(67)$ & $8(18)$ & $36(82)$ & 0.04 \\
\hline Postop & $22(33)$ & $10(45)$ & $12(54)$ & \\
\hline
\end{tabular}

CONTINUED IN NEXT COLUMN »
» CONTINUED FROM PREVIOUS COLUMN

TABLE 1. Patient and disease characteristics

\begin{tabular}{|c|c|c|c|c|}
\hline \multirow[b]{2}{*}{ Variable } & \multicolumn{3}{|c|}{ No. (\%) } & \multirow{2}{*}{$\begin{array}{c}p \\
\text { Value }\end{array}$} \\
\hline & All Tumors & Recurrence & No Recurrence & \\
\hline \multicolumn{5}{|l|}{ Fractionation } \\
\hline Single fraction & $31(47)$ & $5(16)$ & $26(84)$ & 0.10 \\
\hline Multifraction & $35(53)$ & $13(37)$ & $22(63)$ & \\
\hline \multicolumn{5}{|l|}{ BED in Gy } \\
\hline$<50$ & $11(17)$ & $5(45)$ & $6(54)$ & 0.19 \\
\hline $50-59$ & $40(61)$ & $11(28)$ & $29(72)$ & \\
\hline$\geq 60$ & $15(23)$ & $2(13)$ & $13(87)$ & \\
\hline \multicolumn{5}{|l|}{$\begin{array}{l}\text { Vital status at last } \\
\text { FU }\end{array}$} \\
\hline Alive & $9(14)$ & $2(22)$ & $7(78)$ & 1.0 \\
\hline Dead & $57(86)$ & $16(28)$ & $41(72)$ & \\
\hline
\end{tabular}

$\mathrm{CA}=$ cancer; Dediff = dedifferentiated; $\mathrm{Dx}=$ diagnosis; $\mathrm{FU}$ = follow-up; met = metastasis; MFH/UPS = malignant fibrous histiocytoma/undifferentiated pleomorphic sarcoma; NA = not applicable.

\section{Statistical Analysis}

Descriptive statistics were used to evaluate baseline characteristics, and categorical data were analyzed using Fisher's exact test and chi-square analyses. Survival times were calculated from the start date of SSRS to the first occurrence of the considered event. The Kaplan-Meier method was used to estimate rates of overall survival (OS) and LC. Log-rank tests were applied to assess for equality across groups.

The Cox proportional-hazards model was used for univariate and multivariate analyses of OS. Multivariate assessment was done by backward elimination, with all factors with a $p \leq 0.25$ on univariate analysis included in the assessment. Estimated hazard ratios were reported when significant $(\mathrm{p} \leq 0.05)$. For LC and progression-free survival (PFS), a competing risk analysis was performed using the Fine and Gray method; death was treated as a competing risk. Estimated subhazard ratios (SHRs) were reported when significant $(\mathrm{p} \leq 0.05)$. A 2 -sided 5\% significance level was used for analysis. StataCorp statistical software version 13.1 was used for data analysis.

\section{Results}

\section{Cohort Characteristics}

Patient, tumor, and treatment characteristics are summarized in Table 1 . The overall median age was 53 years (range 17-85 years), and 53\% of the patients were female. The most commonly treated sarcoma histology was leiomyosarcoma (28 [42\%]), followed by epithelioid sarcoma $(9[14 \%])$ and malignant fibrous histiocytoma/unclassified pleomorphic sarcoma (8 [13\%]).

At presentation, the majority of tumors were Bilsky Grade $0-1 b(42[64 \%]) .^{2}$ However, patients with higher degrees of cord compression (Bilsky Grades 1c-3) at presentation were more likely to undergo surgery $(\mathrm{p}<0.001)$ than the patients with lower Bilsky grades. Therefore, at 
the time of SSRS treatments, most tumors were Bilsky Grades 0-1b (57 [86\%]), whereas 4 patients (6\%) each had scores of $1 \mathrm{c}$ and 2.

The majority of lesions occurred within the thoracic vertebral bodies (40 [61\%]) and only required treatment to a single vertebral body (48 [73\%]). Most lesions were treated with definitive SSRS alone (44 [67\%]) as opposed to SSRS postoperatively (22 [33\%]), with a fairly equal distribution between single-fraction and multifraction regimens (31 [47\%] vs 35 [53\%], respectively).

A higher proportion of patients who had been treated with postoperative SSRS experienced local recurrence compared with those who had received definitive SSRS ( $45 \%$ vs $18 \%, p=0.04)$. There were no other significant differences between patients with local relapse and those without, including Bilsky grade at the time of SSRS ( $p=$ 0.67; Table 1).

\section{Patterns of Disease Recurrence}

Nineteen patients (29\%) developed local or adjacent vertebral body relapse-local only, 8 patients; in both locations, 10; and in the adjacent vertebral body alone, 1 . The median time to any treatment failure was 8 months (range 1-71 months).

Actuarial 1- and 3-year LC rates were $81 \%$ and $61 \%$, respectively (Fig. 1). Eighteen patients (27\%) had local disease recurrence with a median time of 8 months to failure (range 1-71 months). On multivariate modeling, with death as a competing risk factor, the 2 covariates independently associated with higher LC rates were single vertebral body involvement (vs multiple vertebral bodies, $\mathrm{p}=0.03$, SHR 0.27, 95\% CI 0.08-0.85) and BED > 48 Gy (vs BED $\leq 48$ Gy, p = 0.006, SHR 0.21, 95\% CI 0.07-0.64; Table 2).

To better define patterns of failure, we evaluated local recurrences as infield (3 [17\%]), at the margin within the isodose penumbra (14 [78\%]), or out of field (1 [6\%]; Table $3)$. Among the 3 cases of infield failures, 2 (67\%) had leiomyosarcoma histology. Among the 14 cases of marginal local recurrences, $10(71 \%)$ occurred within the epidural space; the other 4 cases had marginal recurrences within the paraspinal musculature. Retrospective review of these latter cases-3 leiomyosarcoma, 1 alveolar soft part sarcoma-revealed that the CTVs were probably too conservative. For the 1 out-of-field recurrence, retrospective review of pretreatment imaging revealed that the tumor outside the delineated target might have been present prior to treatment.

\section{Overall Survival}

Actuarial 1- and 3-year OS rates were $67 \%$ and $26 \%$ (Fig. 1), respectively, with a median OS of 17 months (range 1-121 months). When variables were assessed using a backward elimination technique, 3 covariates emerged
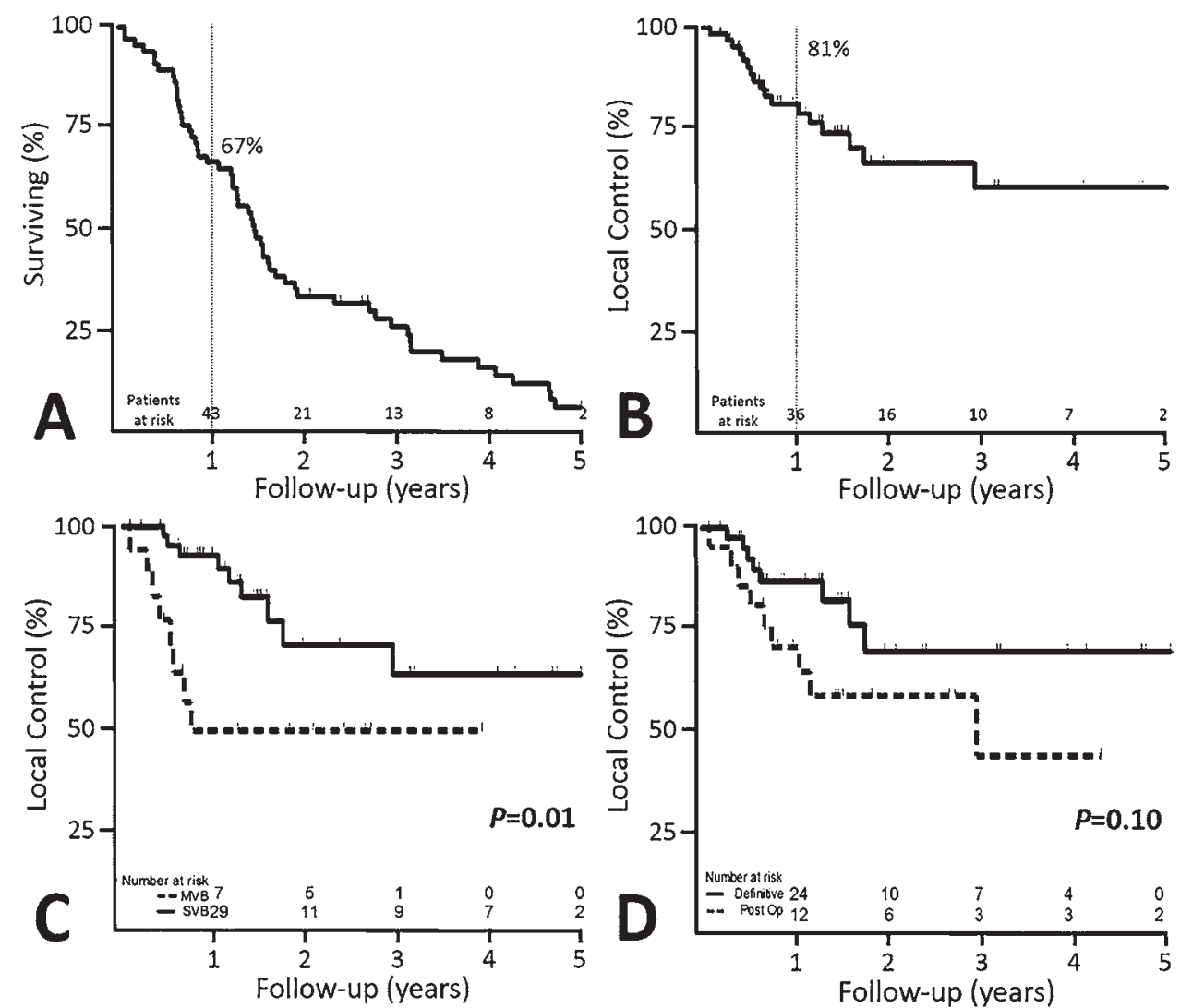

FIG. 1. Outcomes for patients with metastatic sarcoma treated with SSRS: OS (A) and LC (B). Patients with single vertebral body (SVB) involvement had better LC $(p=0.01, C)$, and those with definitive treatment had nearly significantly better LC than those who had postoperative SSRS $(p=0.1, D)$. MVB = multiple vertebral body. 
TABLE 2. Actuarial 1- and 3-year LC rates and competing risk analysis of factors associated with LC

\begin{tabular}{|c|c|c|c|c|}
\hline \multirow[b]{2}{*}{ Parameter } & \multirow{2}{*}{$\begin{array}{l}1-Y r \\
L C \%\end{array}$} & \multirow{2}{*}{$\begin{array}{l}3-Y r \\
\text { LC\% }\end{array}$} & \multicolumn{2}{|c|}{ Univariate Competing Risk } \\
\hline & & & $p$ Value & $\operatorname{SHR}(95 \% \mathrm{Cl})$ \\
\hline RT yr, continuous & - & - & 0.15 & $0.90(0.78-1.04)$ \\
\hline $\begin{array}{l}\text { Age at SSRS treat- } \\
\text { ment, continuous }\end{array}$ & - & - & 0.41 & $0.99(0.95-1.02)$ \\
\hline \multicolumn{5}{|l|}{ Sex } \\
\hline Female & 79 & 62 & & Reference \\
\hline Male & 84 & 59 & 0.94 & $0.97(0.39-2.39)$ \\
\hline \multicolumn{5}{|l|}{ Tumor type } \\
\hline Leiomyosarcoma & 82 & 80 & & Reference \\
\hline Other & 58 & 64 & 0.9 & $0.94(0.38-2.36)$ \\
\hline \multicolumn{5}{|l|}{ Spine section } \\
\hline Cervical & 80 & 80 & & Reference \\
\hline Thoracic & 80 & 61 & 0.81 & $1.17(0.33-4.10)$ \\
\hline Lumbosacral & 82 & 56 & 0.75 & $1.26(0.31-5.13)$ \\
\hline \multicolumn{5}{|l|}{ Vertebral body count } \\
\hline Multiple & 50 & 50 & & Reference \\
\hline Single & 93 & 64 & 0.06 & $0.39(0.14-1.06)$ \\
\hline \multicolumn{5}{|l|}{ Previous RT } \\
\hline No & 79 & 59 & & Reference \\
\hline Yes & 90 & 0 & 0.51 & $0.62(0.15-2.59)$ \\
\hline \multicolumn{5}{|l|}{ Treatment type } \\
\hline Definitive & 87 & 70 & & Reference \\
\hline Postop & 71 & 44 & 0.07 & $2.31(0.92-5.80)$ \\
\hline \multicolumn{5}{|l|}{ Fractionation } \\
\hline Multifraction & 79 & 52 & & Reference \\
\hline Single fraction & 84 & 73 & 0.21 & $0.52(0.19-1.44)$ \\
\hline \multicolumn{5}{|l|}{ BED } \\
\hline$\leq 48 \mathrm{~Gy}$ & 80 & 20 & & Reference \\
\hline$>48 \mathrm{~Gy}$ & 81 & 66 & 0.04 & $0.33(0.12-0.94)$ \\
\hline
\end{tabular}

as independent predictors of survival outcomes: 1) Karnofsky Performance Status (continuous, $\mathrm{p}=0.008$, HR $0.94,95 \%$ CI $0.90-0.98), 2)$ local recurrence $(p=0.001$, HR $0.18,95 \%$ CI 0.07-0.51), and 3) time to local failure (p $<0.001$, HR $1.00,95 \%$ CI 1.00-1.00).

\section{Toxicity}

Based on the CTCAE version 4.3, there were 35 treatment-related acute toxicities (53\%), all of which were either Grade 1 or 2 (no Grade 3 or 4; Table 4). The most common acute toxicity was fatigue (15 cases [23\%] of Grade 1, 5 cases [8\%] of Grade 2). Gastrointestinal toxicities were also relatively common (15 [23\%]). There were $6(9 \%)$ treatment-related instances of nausea, and the midspine (T5-L2) was the SSRS target in all of these cases. Additionally, there were 6 (9\%) episodes of dysphagia (4 cases of Grade 2); 5 of those cases had received SSRS to the cervical spine. Pain flares were uncommon but occurred in 3 patients (4\%) after SSRS, with 2 cases occurring in patients who had received single-fraction SSRS ( $p$ $=0.48$ )
TABLE 3. Characteristics of 18 local failures

\begin{tabular}{|c|c|}
\hline Variable & No. $(\%)$ \\
\hline \multicolumn{2}{|l|}{ Time to LR in mos } \\
\hline Median & 8 \\
\hline Range & $1-71$ \\
\hline \multicolumn{2}{|l|}{ Local failure type } \\
\hline Infield & $3(17)$ \\
\hline Marginal & $14(78)$ \\
\hline Out of field & $1(6)$ \\
\hline \multicolumn{2}{|l|}{ Marginal failure location } \\
\hline Epidural & $10(71)$ \\
\hline Paraspinal & $4(28)$ \\
\hline \multicolumn{2}{|c|}{ Failure in adjacent vertebral bodies } \\
\hline No & 8 \\
\hline Yes & 10 \\
\hline \multicolumn{2}{|l|}{ Explanation for LR } \\
\hline Underdosed & 15 \\
\hline Due to spinal cord & 10 \\
\hline Due to RT vol & 5 \\
\hline Uncertain/biology & 3 \\
\hline \multicolumn{2}{|l|}{ Salvage for LR } \\
\hline Supportive care & 7 \\
\hline Surgery & 5 \\
\hline RT & 4 \\
\hline Surgery + RT & 1 \\
\hline Systemic therapy & 1 \\
\hline
\end{tabular}

$\mathrm{LR}=$ local recurrence.

Late toxicities were less common. There were 4 insufficiency fractures $(6 \%)$ occurring at a median time of 13 months post-SSRS (range 6-23 months), and they were not associated with single- versus multifraction SSRS regimens $(p=0.36)$. While 3 of the insufficiency fractures were relatively asymptomatic, 1 case was particularly concerning, causing severe spinal stenosis and associated myelomalacia, though notably without neuropathies. There were

TABLE 4. Acute and chronic treatment-related toxicities

\begin{tabular}{lrrrrr}
\hline & Total & \multicolumn{4}{c}{ CTCAE Toxicity Score } \\
\cline { 3 - 6 } \multicolumn{1}{c}{ Toxicity } & No. & 1 & 2 & 3 & 4 \\
\hline Acute & & & & & \\
\hline Fatigue & 15 & 10 & 5 & \\
\hline Esophagitis & 6 & 2 & 4 & \\
\hline Nausea & 6 & 4 & 2 & \\
\hline Pain flare & 3 & 1 & 2 & \\
\hline Diarrhea & 3 & 2 & 1 & \\
\hline Dermatitis & 2 & 2 & & \\
\hline Chronic & & & & \\
\hline Insufficiency fracture & 4 & 3 & & 1 \\
\hline Sensory neuropathy & 2 & 1 & 1 & \\
\hline Motor neuropathy & 1 & 1 & & \\
\hline
\end{tabular}


no cases of Grade 3 or 4 late neurological toxicities, but there were 2 patients (3\%) with post-SSRS neuropathies, probably associated with treatment and not disease progression. One patient with a documented history of scleroderma developed both a Grade 1 motor neuropathy (right foot drop and decreased rectal tone) and a Grade 1 sensory neuropathy (bilateral lower-extremity numbness), approximately 13 months after definitive SSRS had been delivered. A separate patient developed neuritis, which caused lowerextremity hyperesthesias and paresthesias, also approximately 13 months following postoperative SSRS.

\section{Discussion}

Local management of sarcoma spinal metastases is challenging given the limited definitive surgical options, the radioresistant nature of this tumor, and the difficulty in delivering meaningful ablative doses using conventional RT. Therefore, the use of highly conformal high-dose SSRS may offer a way to improve outcomes for patients with metastatic sarcoma to the spine. In the current series, we observed favorable local tumor control using SSRS. However, patients who received SSRS after surgery had a higher rate of local recurrence, and a low BED was associated with poorer tumor control. According to our analysis of failure patterns, the majority of local failures were marginal recurrences, commonly occurring in the epidural space (Fig. 2). Importantly, however, several marginal recurrences probably happened because of insufficient treatment volume, particularly when there was soft-tissue extension. Despite relatively high rates of $\mathrm{LC}$ and a favorable toxicity profile associated with SSRS, OS remains poor given the limited systemic options for treating metastatic sarcomas.

With the wide adoption of SSRS, ${ }^{20}$ multiple studies have reported high LC rates above $85 \%$ among all disease histologies. . $^{3,513,14,23,25,29}$ Among the few investigators specifically treating sarcomas, however, the LC rates are not as consistent. ${ }^{6,10,19}$ In the present study, we observed a favorable 1-year LC rate of $81 \%$, which is lower than the rate for other histologies but consistent with the rates in 2 recent series reporting 1-year control rates of $88 \%$ and $78 \% .{ }^{6,10}$ However, authors from the Cleveland Clinic observed a notably lower radiographic control rate (51\% at 12 months). ${ }^{19}$ While this series by Miller and colleagues is a bit of an outlier, it does highlight the difficulty in treating these spine lesions.

Sarcomas have historically been viewed as a relatively radioresistant histology, which underscores the importance of RT dose for local tumor control (Fig. 3). In a study by Kepka and colleagues, higher conventional RT doses were associated with improved LC of gross primary disease ( $<$ $63 \mathrm{~Gy}, 22 \%$ vs $\geq 63 \mathrm{~Gy}, 60 \%$; $\mathrm{p}=0.02) .{ }^{17}$ In our study, we observed that a BED > 48 Gy (Gy/fractions: 24/1, 27/3, 18/1) was significantly associated with improved LC on univariate analysis ( $\mathrm{p}=0.04$, SHR 0.33$)$. Chang and colleagues also reported that higher RT doses were associated with improved 2-year LC rates $(>22 \mathrm{~Gy}, \mathrm{p}=0.03){ }^{6}$ Perhaps lower RT doses (median 16 Gy in 1 fraction, range 10-16 Gy) explain the poorer LC rates observed by Miller and colleagues (51\% at 1 year), ${ }^{19}$ compared with our typi-

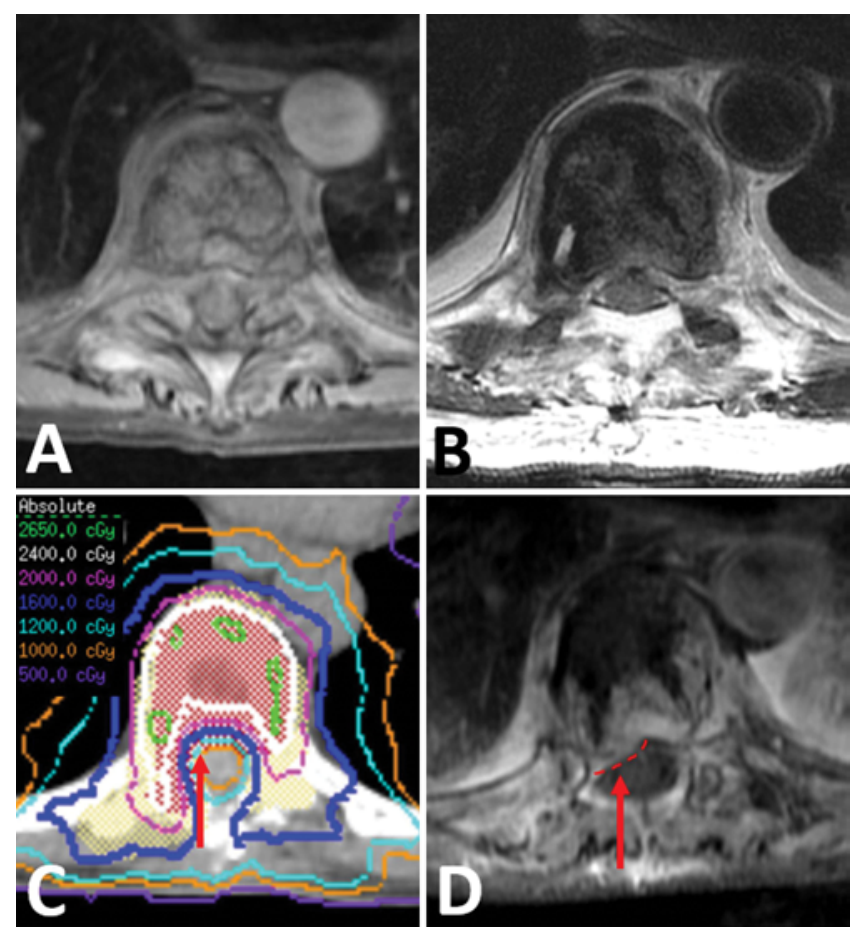

FIG. 2. Illustrative example of an epidural marginal recurrence following SSRS treatment. The patient in this case had metastatic sarcoma with epidural extension (A) that was surgically decompressed (B). It was then treated with SSRS (C) to a dose of $24 \mathrm{~Gy}$ in a single fraction to the GTV and 16 Gy to the CTV. Unfortunately, about 10 months later, the patient had a relapse in the epidural space (red dashed line and arrow, D). Note that this area could not be covered by the prescription dose of $24 \mathrm{~Gy}$ because of spinal cord constraints. Figure is available in color online only.

cal dose of $24 \mathrm{~Gy}$ in 1 fraction or the median dose of 24 Gy reported by authors at Memorial Sloan Kettering Cancer Center (1-year LC 88\%). ${ }^{10}$

One interesting observation from our study is the higher rate of local recurrence in patients treated with postoperative SSRS than in those definitively treated with SSRS alone $(45 \%$ vs $18 \%, \mathrm{p}=0.04)$. This translated into a lower, though not statistically significant, 1-year LC rate among postoperative SSRS patients ( $71 \%$ vs $87 \%$ for definitive SSRS, $p=0.07$, SHR 2.31), with the definitive SSRS patients attaining an LC rate similar to our recently published rate (88\%) among 332 spinal lesions. ${ }^{3}$ The high rate of local relapse following postoperative SSRS for sarcomas was also recently observed by Tao and colleagues, ${ }^{26}$ who reported a 1-year LC rate of $58 \%$ for sarcoma histologies compared with $88 \%$ for nonsarcomatous histologies $(p=0.025)$. Several factors may contribute to a higher relapse rate among postoperative SSRS patients including fractionation, radiation dose, risk of surgical seeding, or radiobiological principles such as devascularization of the tissues resulting in less oxygen delivery.

Fractionation has been associated with LC outcomes of SSRS according to a study by Folkert and colleagues, in which the authors found single-fraction SSRS to be the only factor associated with LC on multivariate analysis (p $=0.03$, HR 0.35). ${ }^{10}$ In contrast, most of the patients in our study who received postoperative SSRS were treated with multifraction regimens (17 [77\%] of 22), commonly 27 Gy 

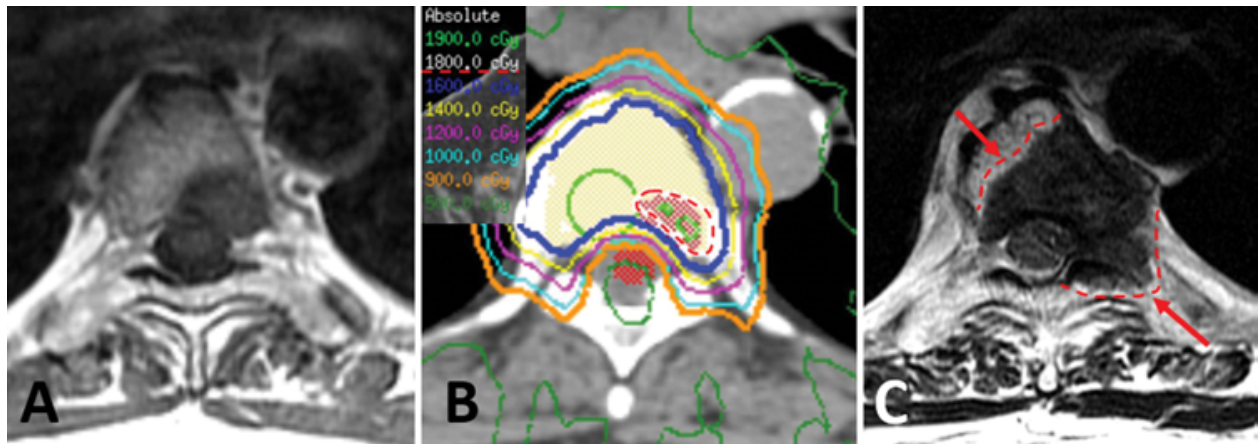

FIG. 3. Illustrative example of an infield recurrence following SSRS treatment. The patient in this case had metastatic sarcoma (A) that was treated with SSRS (B) to a dose of $18 \mathrm{~Gy}$ in a single fraction to the GTV (red color wash and red dashed lines) and 16 Gy to the CTV (vertebral body). Not surprisingly, 18 Gy was not a high enough dose to provide durable LC for this sarcoma histology, and the patient had a relapse (red dashed lines with arrows, $\mathbf{C}$ ) within the irradiated field. Figure is available in color online only.

in 3 fractions (13 [76\%] of 17). Interestingly, the $27 \mathrm{~Gy}$ in 3 fractions that we deliver postoperatively has a BED of $51 \mathrm{~Gy}$, which is lower than what would be prescribed in the postoperative primary sarcoma setting and is far below the threshold for controlling gross disease. ${ }^{17}$ Therefore, while fractionation and the delivered BED may contribute to a higher relapse rate among postoperative SSRS sarcoma patients, the benefits of escalating treatment must be weighed against the risks of injury.

Another complicating feature of sarcoma is its infiltrative, locally aggressive growth patterns. This has treatment implications given the highly conformal delivery of SSRS with no consensus recommendations for treating infiltrating paraspinal disease. Therefore, we performed an analysis of failure patterns to better understand the association between target volume and local recurrences. Of the 18 local recurrences, 14 were classified as marginal failures. Not surprisingly, many of these local failures occurred in the epidural space, which is consistent with previous reports showing that adequate coverage of tumors involving the epidural space close to the spinal cord (within 2-5 $\mathrm{mm}$ ) is challenging. ${ }^{3,5,24}$

However, there were several local relapses that might have been avoided if larger treatment volumes had been used. We observed 4 marginal recurrences that all arose in the paraspinal soft tissue. At the time of treatment planning, there were probably inadequate CTV expansions applied to these cases to account for the microscopically invasive nature of sarcomas. Better definition of appropriate treatment volumes is particularly important given the high proportion of sarcoma patients who have paraspinal extension; in a report by Bilsky and colleagues, nearly $70 \%$ of the patients presenting with bone involvement also had soft-tissue extension. ${ }^{2}$ Similarly, Miller and colleagues reported $60 \%$ of cases with paraspinal extension. ${ }^{19}$ They also found that involvement of the posterior elements was associated with radiographic failure $(\mathrm{p}=0.04, \mathrm{HR} 2.16)$, which may also be related to paraspinal extension. Given the relatively restrictive space for growth within the posterior elements, metastatic deposits tend to erode through the bony cortex and extend into the paraspinal space. If adequate CTV expansions are not applied, local tumor control is less likely.

Several years ago the International Spine Radiosurgery
Consortium published a recommendation for guidance on SSRS contouring. ${ }^{9}$ While it expressly recommended no extraosseous CTV expansion for bone-only disease, there were no specific guidelines for coverage of paraspinal extension of disease or paraspinal metastases. Alternatively, if we examine the guidelines for target delineation of extremity sarcomas, 2 consensus statements recommend a 3- to 4-cm longitudinal expansion of the GTV and a 1.5-cm radial expansion. ${ }^{15,27}$ These recommendations are based on historical pathological studies, including one showing that $60 \%$ of cases with satellite tumor cells outside the primary sarcoma tumor were within $1 \mathrm{~cm}$, whereas $40 \%$ were within $1-4 \mathrm{~cm} .{ }^{28}$ Therefore, if we extrapolate from the available literature, for sarcomas metastatic to vertebral bodies that erode through the cortex into the paraspinal soft tissue, we recommend considering a larger radial CTV expansion (perhaps $1.5 \mathrm{~cm}$ ) into soft tissue since this type of growth may be less longitudinally infiltrative along fascial planes. However, perhaps sarcomas metastatic directly to the paraspinal tissues warrant target delineation more similar to primary sarcomas with a generous longitudinal CTV expansion along the paraspinal musculature.

This study provides additional evidence of durable LC rates using SSRS for sarcoma metastases and, importantly, contributes a unique pattern-of-failure analysis to help reconcile the 2 vastly different RT paradigms. However, as with any retrospective analysis, there are inherent limitations when interpreting the results. First, while this study represents a relatively large series, considering the paucity of data for SSRS to sarcoma metastases, the number of patients and subsequent local recurrences are few, which limits the robustness of the analysis. Second, this study does incorporate patients enrolled in our early institutional trials, which may have treated patients more conservatively than is our current practice. Third, while about half of the patients in the current study were followed prospectively, some of the toxicity data were retrospectively extracted. The most commonly observed acute toxicity was fatigue (23\%), and there were no Grade 3 toxicities; Folkert and colleagues reported similar acute toxicities. ${ }^{10} \mathrm{We}$ also observed few late toxicities (4 compression fractures, 3 neuropathies), but we acknowledge the difficulty in retrospectively identifying treatment-related side effects. 


\section{Conclusions}

Spine stereotactic radiosurgery for sarcoma metastases is a viable option for providing durable $\mathrm{LC}$ with minimal toxicity. According to our data and the available literature, doses $\geq 22$ Gy in a single fraction provide optimal tumor control. ${ }^{6,10}$ Additionally, we observed a higher rate of local relapse in postoperative SSRS cases, which is also probably attributable to the RT dose and fractionation. In our analysis of patterns of failure, we found that the majority of relapses occurred within the epidural canal. However, in a small proportion of cases, more generous treatment volumes could minimize the risk of relapse. Specifically, in cases with paraspinal extension eroding through bone cortex, we recommend considering a larger CTV expansion (perhaps $1.5 \mathrm{~cm}$ ) into the soft tissue, which is extrapolated from existing sarcoma consensus guidelines. For patients who have paraspinal metastases, more generous longitudinal expansions are probably warranted. In our continued pursuit of improved SSRS target delineation and conformality, we should remember the biological behavior of individual cancer types and the principles by which they shape our treatment volumes.

\section{Acknowledgments}

This research was supported in part by the Cancer Center Support (Core) Grant No. CA016672 to The University of Texas MD Anderson Cancer Center.

\section{References}

1. Amdur RJ, Bennett J, Olivier K, Wallace A, Morris CG, Liu C, et al: A prospective, phase II study demonstrating the potential value and limitation of radiosurgery for spine metastases. Am J Clin Oncol 32:515-520, 2009

2. Bilsky MH, Boland PJ, Panageas KS, Woodruff JM, Brennan MF, Healey JH: Intralesional resection of primary and metastatic sarcoma involving the spine: outcome analysis of 59 patients. Neurosurgery 49:1277-1287, 2001

3. Bishop AJ, Tao R, Rebueno NC, Christensen EN, Allen PK, Wang XA, et al: Outcomes for spine stereotactic body radiation therapy and an analysis of predictors of local recurrence. Int J Radiat Oncol Biol Phys 92:1016-1026, 2015

4. Chang EL, Shiu AS, Lii MF, Rhines LD, Mendel E, Mahajan A, et al: Phase I clinical evaluation of near-simultaneous computed tomographic image-guided stereotactic body radiotherapy for spinal metastases. Int J Radiat Oncol Biol Phys 59:1288-1294, 2004

5. Chang EL, Shiu AS, Mendel E, Mathews LA, Mahajan A, Allen PK, et al: Phase I/II study of stereotactic body radiotherapy for spinal metastasis and its pattern of failure. $\mathbf{J}$ Neurosurg Spine 7:151-160, 2007

6. Chang UK, Cho WI, Lee DH, Kim MS, Cho CK, Lee SY, et al: Stereotactic radiosurgery for primary and metastatic sarcomas involving the spine. J Neurooncol 107:551-557, 2012

7. Christie-Large M, James SL, Tiessen L, Davies AM, Grimer RJ: Imaging strategy for detecting lung metastases at presentation in patients with soft tissue sarcomas. Eur $\mathbf{J}$ Cancer 44:1841-1845, 2008

8. Coleman RE: Clinical features of metastatic bone disease and risk of skeletal morbidity. Clin Cancer Res 12:6243s-6249s, 2006

9. Cox BW, Spratt DE, Lovelock M, Bilsky MH, Lis E, Ryu $\mathrm{S}$, et al: International Spine Radiosurgery Consortium consensus guidelines for target volume definition in spinal stereotactic radiosurgery. Int J Radiat Oncol Biol Phys 83:e597-e605, 2012

10. Folkert MR, Bilsky MH, Tom AK, Oh JH, Alektiar KM, Laufer I, et al: Outcomes and toxicity for hypofractionated and single-fraction image-guided stereotactic radiosurgery for sarcomas metastasizing to the spine. Int J Radiat Oncol Biol Phys 88:1085-1091, 2014

11. Garg AK, Shiu AS, Yang J, Wang XS, Allen P, Brown BW, et al: Phase 1/2 trial of single-session stereotactic body radiotherapy for previously unirradiated spinal metastases. Cancer 118:5069-5077, 2012

12. Garg AK, Wang XS, Shiu AS, Allen P, Yang J, McAleer MF, et al: Prospective evaluation of spinal reirradiation by using stereotactic body radiation therapy: the University of Texas MD Anderson Cancer Center experience. Cancer 117:35093516, 2011

13. Gerszten PC, Burton SA, Ozhasoglu C, Welch WC: Radiosurgery for spinal metastases: clinical experience in 500 cases from a single institution. Spine (Phila Pa 1976) 32:193-199, 2007

14. Gerszten PC, Mendel E, Yamada Y: Radiotherapy and radiosurgery for metastatic spine disease: what are the options, indications, and outcomes? Spine (Phila Pa 1976) 34 (22 Suppl):S78-S92, 2009

15. Haas RL, Delaney TF, O'Sullivan B, Keus RB, Le Pechoux C, Olmi P, et al: Radiotherapy for management of extremity soft tissue sarcomas: why, when, and where? Int J Radiat Oncol Biol Phys 84:572-580, 2012

16. Katagiri H, Takahashi M, Inagaki J, Kobayashi H, Sugiura H, Yamamura S, et al: Clinical results of nonsurgical treatment for spinal metastases. Int J Radiat Oncol Biol Phys 42:1127-1132, 1998

17. Kepka L, DeLaney TF, Suit HD, Goldberg SI: Results of radiation therapy for unresected soft-tissue sarcomas. Int J Radiat Oncol Biol Phys 63:852-859, 2005

18. Leeman JE, Bilsky M, Laufer I, Folkert MR, Taunk NK, Osborne JR, et al: Stereotactic body radiotherapy for metastatic spinal sarcoma: a detailed patterns-of-failure study. J Neurosurg Spine 25:52-58, 2016

19. Miller JA, Balagamwala EH, Angelov L, Suh JH, Djemil T, Magnelli A, et al: Stereotactic radiosurgery for the treatment of primary and metastatic spinal sarcomas. Technol Cancer Res Treat 64 (2 Suppl):A54-A59, 2009, 2016

20. Pan H, Simpson DR, Mell LK, Mundt AJ, Lawson JD: A survey of stereotactic body radiotherapy use in the United States. Cancer 117:4566-4572, 2011

21. Pan HY, Allen PK, Wang XS, Chang EL, Rhines LD, Tatsui $\mathrm{CE}$, et al: Incidence and predictive factors of pain flare after spine stereotactic body radiation therapy: secondary analysis of phase 1/2 trials. Int J Radiat Oncol Biol Phys 90:870876,2014

22. Rao G, Suki D, Chakrabarti I, Feiz-Erfan I, Mody MG, McCutcheon IE, et al: Surgical management of primary and metastatic sarcoma of the mobile spine. J Neurosurg Spine 9:120-128, 2008

23. Ryu S, Jin JY, Jin R, Rock J, Ajlouni M, Movsas B, et al: Partial volume tolerance of the spinal cord and complications of single-dose radiosurgery. Cancer 109:628-636, 2007

24. Sahgal A, Larson DA, Chang EL: Stereotactic body radiosurgery for spinal metastases: a critical review. Int J Radiat Oncol Biol Phys 71:652-665, 2008

25. Sahgal A, Weinberg V, Ma L, Chang E, Chao S, Muacevic A, et al: Probabilities of radiation myelopathy specific to stereotactic body radiation therapy to guide safe practice. Int J Radiat Oncol Biol Phys 85:341-347, 2013

26. Tao R, Bishop AJ, Brownlee Z, Allen PK, Settle SH, Chang EL, et al: Stereotactic body radiation therapy for spinal metastases in the postoperative setting: a secondary analysis 
of mature phase 1-2 trials. Int J Radiat Oncol Biol Phys 95:1405-1413, 2016

27. Wang D, Bosch W, Roberge D, Finkelstein SE, Petersen I, Haddock M, et al: RTOG sarcoma radiation oncologists reach consensus on gross tumor volume and clinical target volume on computed tomographic images for preoperative radiotherapy of primary soft tissue sarcoma of extremity in Radiation Therapy Oncology Group studies. Int J Radiat Oncol Biol Phys 81:e525-e528, 2011

28. White LM, Wunder JS, Bell RS, O'Sullivan B, Catton C, Ferguson P, et al: Histologic assessment of peritumoral edema in soft tissue sarcoma. Int J Radiat Oncol Biol Phys 61:1439-1445, 2005

29. Yamada Y, Bilsky MH, Lovelock DM, Venkatraman ES, Toner S, Johnson J, et al: High-dose, single-fraction imageguided intensity-modulated radiotherapy for metastatic spinal lesions. Int J Radiat Oncol Biol Phys 71:484-490, 2008

30. Zagars GK, Ballo MT, Pisters PW, Pollock RE, Patel SR, Benjamin RS, et al: Prognostic factors for patients with localized soft-tissue sarcoma treated with conservation surgery and radiation therapy: an analysis of 1225 patients. Cancer 97:2530-2543, 2003

\section{Disclosures}

Dr. Chang has received honoraria from Elekta and BrainLab for travel and speaking engagements. Dr. Rhines is a consultant for Stryker and Globus.

\section{Author Contributions}

Conception and design: Bishop, Tao, Ghia. Acquisition of data: Bishop, Tao. Analysis and interpretation of data: Bishop, Tao, Ghia. Drafting the article: Bishop, Tao, Guadagnolo, Ghia. Critically revising the article: all authors. Reviewed submitted version of manuscript: all authors. Approved the final version of the manuscript on behalf of all authors: Bishop. Statistical analysis: Bishop, Allen.

\section{Correspondence}

Andrew J. Bishop, Department of Radiation Oncology, Unit 97, The University of Texas MD Anderson Cancer Center, 1515 Holcombe Blvd., Houston, TX 77030. email: abishop2@ mdanderson.org. 